\title{
Inclusão escolar, ensino de matemática e pandemia: algumas consideraçōes
}

Tatiana Bolivar Lebedeff*, Thaís Philipsen Grutzmann**

\section{Resumo}

O presente artigo tem como objetivo problematizar e refletir sobre o conceito de Inclusão no que concerne ao ensino de Matemática. Para tanto, utiliza como pano de fundo as memórias docentes das autoras para discutir a formação de professores, os subsídios legais e as condições da escola para a Inclusão, tanto em situação de pré-pandemia como em momento de pandemia.

Palavras-Chave: Inclusão escolar; Matemática Inclusiva; Inclusão em tempos de Pandemia.

\section{Introdução}

Este texto tem como "pretensão" discutir e problematizar o conceito de inclusão com relação à disciplina de Matemática. Quando nos propomos, inicialmente, a escrever este texto, a Pandemia do Covid-19 ainda não assolava nossas terras e não fechava nossas escolas. Tínhamos uma perspectiva de Inclusão muito centrada em nossas experiências como docentes de uma Instituição Pública de Ensino Superior, nas nossas práticas de pesquisa e, nas orientações de estágio, ou seja, uma bolha pedagógica.

Entretanto, a pandemia e o fechamento das escolas desvelou outras exclusões, que já sabíamos existir mas, estavam distantes de nossas salas de aula (nossa bolha). Paradoxalmente, o distanciamento físico o fechamento das escolas trouxeram para dentro de nossas casas, via mídias sociais, a realidade de escolas, de docentes e discentes neste vasto e desigual país.

Doutora em Psicologia do Desenvolvimento pela UFRGS, Mestre em Educação pela UERJ, Especialista em Educação a Distância pela UFPR, Graduada em Educação Especial pela UFSM. Professora do Centro de Letras e Comunicação da UFPEL. Brasil. E-mail: tblebedeff@gmail.com

* Doutora em Educação pela UFPEL, Mestre em Educação em Ciências e Matemática pela PUCRS, Especialista em Educação - com ênfase na Educação de Surdos pela UFPEL e, em Matemática e Linguagem pela UFPEL; Licenciada em Matemática pela UFPEL. Professora do Instituto de Física e Matemática da UFPEL. Brasil. E-mail: thaisclmd2@gmail.com

https://doi.org/10.5335/rbecm.v3i3.11835

http://creativecommons.org/licenses/by-nc-nd/4.0 
As informações sobre as condições de escolarização pré e, em momento de Pandemia, sacudiram algumas de nossas compreensões sobre a Inclusão e nos mobilizaram a escrever este texto que trilhará percursos diversos, sem o propósito de ser um artigo científico com dados de nossas pesquisas. Será, portanto, um misto de ensaio com algumas narrativas de nossas memórias docentes.

Salientamos que este texto é uma pretensão de discussão porque compreendemos que não é tarefa fácil, hodiernamente, discutir e problematizar Inclusão. Espera-se, entretanto, que o texto possa contribuir para a reflexão sobre o conceito de Inclusão (compreendido, aqui, como difuso, multifacetado e, porque não, problemático) e, que possibilite novas inferências aos leitores.

\section{Conceito e práticas difusas}

Na produção do texto nos deparamos com alguns artigos que mobilizaram, sobremaneira, nossas discussões. Veiga-Neto e Lopes (2007), por exemplo, discutiam há 13 anos que, naquele momento, não seria um exagero afirmar que a inclusão era um dos temas mais candentes e difíceis nas discussões brasileiras sobre educação. Alertavam, então que:

[...] na maioria dos acalorados debates sobre o assunto, sobram opiniões e posicionamentos políticos, mas faltam clareza e objetividade sobre aquilo que é dito. Isso é assim não apenas porque a inclusão é um tema que só recentemente entrou na agenda das políticas públicas, mas, também, porque, sob essa palavra, coloca-se em jogo um intrincado conjunto de variáveis sociais e culturais que vão desde princípios e ideologias até interesses e disputas por significação (VEIGA-NETO; LOPES, 2007; p. 948).

Os autores chamavam a atenção para a multiplicidade de discursos acerca da inclusão e as dificuldades na objetivação de uma prática de inclusão, na escola. Ou seja, sobravam discursos e faltavam dispositivos de materialização do que seria a inclusão escolar. Entretanto, a esta época, o Brasil já havia sido um dos signatários da Declaração de Salamanca (BRASIL/MAS, 1994) que, internacionalmente, indicava a necessidade de uma "Educação para Todos". A Declaração de Salamanca foi um documento balizador para para as Diretrizes Nacionais para a Educação Especial na Educação Básica (CNE/CEB, 2001), para o documento Parâmetros Curriculares Nacionais - Adaptações Curriculares (MEC, 1999) para o documento denominado "Estratégias para a educação de alunos com necessidades educacionais especiais" (MEC/SEESP, 2003), entre outros que não serão, aqui, nomeados. 
A produção do texto eliciou várias memórias, dentre elas a de uma experiência de formação continuada em um município na Região Norte do Estado do RS, realizado em 1997 (ou 1998). Na ocasião, uma das autoras ouviu o relato de uma mãe de uma criança que tinha epilepsia e, por isso, tomava medicamentos que comprometiam a motricidade fina. O menino, relatou a mãe, era campeão de xadrez na escola e fazia contas com cálculo mental. Entretanto, ele ficava na sala durante o recreio, todos os dias que tinha Matemática, porque não conseguia copiar do quadro, em tempo hábil, os problemas matemáticos.

Ficamos pensando em diversas opções, alternativas, para a simples cópia dos problemas. Nos questionamos o que a cópia, enquanto atividade por si só, evidenciaria em termos de aprendizagens. Nada nos justificou o "castigo" por algo que o menino não tinha absoluto controle.

A memória tem uma pluralidade de funções em correlação, não meramente em sequência factual e temporal; constitui-se um campo da dialética temporal e dos fenômenos sociais (TEDESCO, 2011, p. 13). Deste modo, segundo o autor, a memória não se dissocia dos fenômenos culturais e dos tempos das sociedades, pelo contrário, a memória auxilia na reprodução e na dinâmica interpretativa dos mesmos, além desses fenômenos constituírem-se parte da identidade do sujeito em relação ao lugar que habita.

A memória eliciada nos levou a ampliar a busca por documentos que auxiliassem a contextualizar e interpretar a situação e nos deparamos com a Portaria N.. 1.793 (MEC/SEESP, 1994). Esta Portaria recomendava, em 1994, em apenas dois artigos, a inclusão de uma disciplina, nos cursos de Licenciaturas, com finalidade de preparar os professores em formação, para a docência de alunos com deficiência:

Art.1ํ. Recomendar a inclusão da disciplina "ASPECTOS ÉTICO-POLITICO EDUCACIONAIS DA NORMALIZAÇÃO E INTEGRAÇÃO DA PESSOA PORTADORA DE NECESSIDADES ESPECIAIS", prioritariamente, nos cursos de Pedagogia, Psicologia e em todas as Licenciaturas.

Art. $2^{\circ}$. Recomendar a inclusão de conteúdos relativos aos aspectos-Ético-Políticos- Educacionais da Normalização e Integração da Pessoa Portadora de Necessidades Especiais nos cursos do grupo de Ciência da Saúde (Educação Física, Enfermagem, Farmácia, Fisioterapia, Fonoaudiologia, Medicina, Nutrição, Odontologia, Terapia Ocupacional), no Curso de Serviço Social e nos demais cursos superiores, de acordo com as suas especificidades.

Apesar da terminologia já defasada (Normalização e Integração), percebe-se que a Portaria indicava uma mudança significativa que ocorreria nas escolas: os estudantes com deficiências sairiam das escolas especiais e adentrariam as classes comuns 
das escolas regulares e, sendo assim, os professores deveriam estar aptos a ensinar Geografia, Biologia, Matemática, entre outras disciplinas, para esses estudantes. A data da Portaria desvela que, se tivesse sido tomada em sério, talvez o menino não estivesse sofrendo, subjugado a um trabalho de cópia sem muita serventia para seu desenvolvimento. A portaria veio ao encontro da discussão que estamos fazendo em nossa pesquisa, de que 1) precisamos conhecer a diferença do nosso aluno, ou seja, se existe uma norma para a qual este aluno é categorizado como "excluído", temos que conhecer o que lhe diferencia e o porquê esta diferença o exclui e, 2) uma vez conhecendo a diferença, conhecer como e, o que fazer em sala de aula, no tocante ao ensino de Matemática (Biologia, Línguas, Física, História, entre outras disciplinas escolares), ou seja, em como criar condições para que norma e diferença estejam juntos e, se beneficiem, mutuamente, deste estar juntos.

Pensar a Educação Matemática num contexto para todos, é, justamente, a finalidade para a qual o termo "Educação Matemática Inclusiva" vem sendo utilizado. Um grupo de educadores matemáticos, engajados em pesquisas das diferentes áreas do cenário inclusivo, criaram, em 2013, o "Grupo de Trabalho Diferença, Inclusão e Educação Matemática da Sociedade Brasileira de Educação Matemática (SBEM) - o GT13" (NOGUEIRA et al., 2019, p. 5).

$\mathrm{Na}$ visão desses educadores compreende-se que é importante "valorizar a contribuição ativa de todos os estudantes, de acordo com suas potencialidades" (NOGUEIRA et al., 2019, p. 7). Dentre as discussões do grupo existem diferentes temáticas de pesquisa, vinculadas a espaços formais e não-formais de ensino, vinculadas não somente a questão das pessoas com deficiências, mas a outros grupos minoritários. Destacam-se pesquisas envolvendo pessoas com surdez/deficiência auditiva, cegueira/baixa visão, surdocegueira, síndrome de Down, Transtorno do Espectro Autista e diversas outras condições, transitórias ou permanentes, tais como as altas habilidades, dificuldades específicas de aprendizagem de matemática, idosas, entre outras (NOGUEIRA et al., 2019).

Nas pesquisas realizadas pelos membros do GT 13 "visam-se abordar estudos que contribuam com a estruturação de uma Educação Matemática que favoreça uma compreensão profunda dos processos de ensino e de aprendizagem, focando questões teóricas, metodológicas, pedagógicas e epistemológicas" (NOGUEIRA et al., 2019, p. 7).

Em contexto nacional, existem importantes eventos que dialogam com a Educação Matemática com grupos de trabalho/discussão pensados para a inclusão: no Seminário 
Internacional de Pesquisa em Educação Matemática (SIPEM) o grupo de trabalho Diferença, inclusão e Educação Matemática (GT13), no Encontro Nacional de Educação Matemática (ENEM) o subeixo Práticas inclusivas em Educação Matemática e, no Encontro Brasileiro de Estudantes de Pós-Graduação em Educação Matemática (EBRAPEM) o grupo de discussão Educação Matemática e Inclusão (GD 13).

Tendo em vista a data da Portaria e seu conteúdo e, todo o movimento da "Educação Matemática Inclusiva”, fomos em busca dos Projetos Pedagógicos de Cursos (PPC) de Licenciatura em Matemática. Buscamos apenas os que ficavam geograficamente perto de nossa instituição, para ter um pequeno parâmetro de como e, principalmente, se, haveria a oferta de disciplinas que abordassem inclusão. Como a análise dos PPCs não é o objetivo deste texto, invadimos apenas os PPCs da FURG, UNIPAMPA e UFPEL.

A FURG oferece a disciplina de Educação Matemática e Docência III no terceiro semestre, cuja ementa apresenta os seguintes conteúdos:

Finalidades, práticas e movimentos de inovação da Matemática Escolar. A profissionalização dos professores de Matemática no Brasil. Reflexão crítica de questões ético-políticoeducacionais da ação docente quanto à integração/inclusão escolar de pessoas com necessidades educativas especiais. Análise da evolução conceitual, na área da educação especial, assim como as mudanças paradigmáticas e as propostas de intervenção. Discussão sobre as atuais tendências, considerando a relação entre a prática pedagógica e a pesquisa em âmbito educacional no ensino de Matemática (FURG, 2020; p. 23).

Já a Unipampa oferta a disciplina de Educação Inclusiva no $2^{\circ}$ semestre do curso, apresentando a seguinte ementa:

Fundamentos teóricos e metodológicos da inclusão. Legislação e políticas públicas que amparam o processo no país. Necessidades educacionais especiais e a prática pedagógica. Objetivos: Compreender os paradigmas filosóficos, legais e metodológicos da educação inclusiva; Conhecer os marcos legais que sustentam o processo no país; Discutir sobre as políticas educacionais inclusivas desenvolvidas no contexto educacional internacional, nacional e local; Analisar as implicações do processo de inclusão do aluno com necessidades educativas especiais na escola regular e na comunidade; Estudar as diferentes necessidades educacionais especiais, conhecendo suas características e formas de intervenção pedagógica (UNIPAMPA, 2020; p. 68).

A UFPEL, infelizmente, não possui disciplinas que tratem, especificamente ou, ainda, que apresente conteúdos direcionados à inclusão. Uma rápida leitura das ementas já permite compreender que talvez, em apenas um semestre, seria impossível conhecer as diferenças e as estratégias didático-pedagógicas para dar conta do ensino de Matemática na Escola Inclusiva. 
A correlação entre as recomendações da Portaria e os PPCs dos cursos de Licenciatura em Matemática das três instituições dispararam outra memória, a de uma situação ocorrida recentemente, no primeiro semestre de 2020. Na disciplina Seminário Integrador III a professora fez a proposta de produção de um plano de aula, para uma turma que teria dois alunos surdos e o TILS. Um estudante, do $8^{\circ}$ semestre, argumentou que não haveria necessidade de nenhuma modificação ou adaptação, pois, segundo ele: - Se eu tenho um aluno surdo não preciso fazer nada, a escola já vai ter Intérprete.

Nossas memórias apresentam a fotografia de uma representação de "não necessidade de modificação para a diferença" materializada na prática docente e, no planejamento. Os dois fatos separados por, aproximadamente, incríveis 22 anos explicitam falta de conhecimento e, porque não, de empatia com a diferença. Paradoxalmente, não falta legislação, nem publicações governamentais, e, muito menos, produções acadêmicas que auxiliem na compreensão da diferença e, da docência para a diferença. Aqui não se quer falar em "receitas para a inclusão", mas, em conhecimento socialmente produzido e experiências documentadas que podem ser acionadas na escola. $\mathrm{O}$ estudante de oitavo semestre, pode-se inferir, nunca teve colegas "diferentes", nem na escola e, nem na Graduação.

Mendes (2017) comenta que "a despeito do aparente consenso sobre o princípio filosófico da inclusão escolar, dificilmente se encontra na literatura uma definição precisa para esse termo (MENDES, 2017; p. 74)". Entretanto, segundo a autora, a característica principal tem sido a garantia de oportunidade de plena participação dos estudantes com deficiência nas salas de aulas comuns de escolas regulares. A partir desta garantia, segue a autora, princípios foram e, acreditamos, seguem sendo gerados. Princípios tais como:

1) que todas as crianças e jovens $\mathrm{PAEE}^{1}$ devem ser escolarizados nas classes comuns das escolas regulares; portanto, a princípio, ninguém deve ser excluído com base no grau ou tipo de deficiência; 2) que todas as crianças e jovens PAEE devem ser escolarizados nas classes comuns das escolas regulares de seus bairros (e para onde iriam se não fossem identificados como estudantes PAEE?); 3) que, nessas escolas comuns, todas as crianças e jovens PAEE devam receber oportunidades acadêmicas e extracurriculares apropriadas a sua idade cronológica e iguais à de seus pares; 4) que todas essas crianças e jovens PAEE e seus professores recebam todos os apoios de que precisam, no contexto da classe comum, para serem devidamente escolarizados; 5) que todas essas crianças e jovens PAEE tenham assegurado o sucesso acadêmico, comportamental e social, de modo a maximizar a inserção pessoal e social futura desses estudantes na comunidade (MENDES, 2017; p. 74-75). 
Conforme é possível inferir, compreender e adotar, na escola, esses princípios, não é tarefa simples, pois, é necessário que a escola esteja dotada de condições estruturais e, os docentes, capacitados a trabalhar com as diferenças. Além disso, é necessário garantir alicerce para o trabalho pedagógico, como o exemplificado por Bueno (2016): a) não centralizar o atendimento dos alunos nas Salas de Recursos Multifuncionais; b) as atividades desenvolvidas no Atendimento Educacional Especializado devem ser diferenciadas daquelas realizadas na sala de aula comum, não sendo substitutivas à escolarização; c) oferta de transporte escolar acessível; d) adequações arquitetônicas e de mobiliário, com disponibilização de equipamentos e de material didático adaptado; e) a revisão, tanto as políticas curriculares, quanto da organização do processo pedagógico nas escolas, a fim de que os potenciais dos alunos da educação especial possam ser aproveitados, com a adoção de práticas pedagógicas diversificadas; f) a presença, na escola, de outros profissionais da educação, tais como o tradutor intérprete de Língua Brasileira de Sinais, guia-intérprete e outros que atuem no apoio, principalmente nas atividades de alimentação, higiene e locomoção, entre muitos outros dispositivos garantidos em lei.

Até aqui comentamos sobre a dificuldade de um consenso sobre o conceito de Inclusão, sobre a existência de uma legislação não cumprida e, sobre algumas demandas, não atendidas, para uma educação inclusiva. Se as condições atuais, sem Pandemia do Covid-19, já não eram as ideais para garantir acesso, permanência e igualdade de condições para aprendizagem, questiona-se a inclusão em tempos de fechamento de escolas e necessidade de isolamento social.

\section{Inclusão e Pandemia}

Em tempos de pandemia do Covid-19, Abreu (2020; p. 156) comenta que

[...] para a educação tornar-se inclusiva os materiais necessários, prioritariamente, são os suportes tecnológicos, como equipamentos eletrônicos e acesso à internet, para estabelecer a interatividade e acessar as atividades disponibilizadas nos ambientes virtuais.

Entretanto, os resultados da pesquisa TIC Educação de 2018 (publicada em 2019) mostram uma realidade não muito promissora em termos de suportes tecnológicos para a educação. A pesquisa TIC Educação é desenvolvida pelo Comitê Gestor da Internet no Brasil que produz, regularmente, estatísticas e indicadores sobre o acesso e uso das tecnologias de informação e comunicação (TIC) no país. 
Barbosa (2019), no capítulo de introdução do livro que apresenta os resultados da pesquisa, salienta alguns dados preocupantes com relação ao acesso dos estudantes brasileiros a dispositivos tecnológicos e internet:

[...] segundo os dados coletados em 2018, aproximadamente $30 \%$ dos alunos que estudam em escolas localizadas em áreas urbanas não possuíam nenhum tipo de computador no domicílio (tablet, computador portátil ou de mesa). Entre os alunos usuários de Internet, 18\% deles acessaram a rede exclusivamente pelo telefone celular, sendo que a proporção era maior entre os estudantes de escolas públicas (21\%) e habitantes da região Norte (31\%) e Nordeste (32\%). Nas áreas rurais, apenas $34 \%$ das escolas possuíam ao menos um computador com acesso à Internet, percentual que foi de apenas 14\% na região Norte, em 2018 (BARBOSA, 2018, p. 28).

Com relação a conectividade na escola, a TIC Educação 2018 apresenta dados que desvelam uma escola que não disponibiliza, aos seus estudantes, experiências de construção de conhecimento utilizando as tecnologias digitais, pois as escolas apresentam a seguinte configuração:

A pesquisa aponta que apenas $25 \%$ das instituições localizadas em áreas urbanas possuíam mais de 16 computadores de mesa em funcionamento para uso dos alunos, $9 \%$ possuíam mais de seis computadores portáteis e $12 \%$, mais de seis tablets. Considerando que, em 2018, grande parte das escolas contavam com mais de 26 alunos por turma ( $37 \%$ entre as escolas que atendem estudantes de Ensino Fundamental II e 25\% entre aquelas que atendem estudantes de Ensino Médio), possivelmente, nestas instituições, o número de alunos por dispositivo fosse bastante alto, especialmente em relação aos dispositivos móveis. A obsolescência dos equipamentos - dificuldade apontada por $76 \%$ dos diretores de escolas públicas urbanas e $49 \%$ dos diretores de escolas particulares - é uma das principais causas de carência de oferta de dispositivos para uso pedagógico nas escolas (TIC EDUCAÇÃO 2018, 2019, p. 119).

Além de não ter não disponibilizar dispositivos para a prática pedagógica, as escolas também não disponibilizam internet para seus estudantes e professores. De acordo com a pesquisa:

[...] a escola não se configura como um local prioritário de uso da Internet entre os alunos, uma vez que a proporção de estudantes que mencionaram o ambiente escolar foi de pouco mais de um terço (37\%). Entre os alunos das três séries de interesse investigadas no estudo, o uso da rede na escola foi mais comum entre aqueles do $2^{\circ}$ ano do Ensino Médio (62\%) e do $9^{\circ}$ ano do Ensino Fundamental (41\%), enquanto, entre os alunos do $5^{\circ}$ ano do Ensino Fundamental, apenas um em cada dez (12\%) disse acessar a Internet na escola. O uso da Internet na escola foi também inferior ao acesso à rede realizado em outros locais investigados pela pesquisa, como, por exemplo, em locais públicos (shoppings, igrejas ou lanchonetes - 57\%) e enquanto se deslocam, como na rua ou em diferentes meios de transporte (52\%) (TIC EDUCAÇÃO 2018, 2019, p. 127). 
Para além da tecnologia digital, também temos que analisar o acesso, dos nossos estudantes, a outros tipos de tecnologia. O Instituto "Trata Brasil” é uma OSCIP (Organização da Sociedade Civil de Interesse Público) que atua no saneamento básico e na proteção dos recursos hídricos do país. O Instituto, em sua página na web, apresenta um resumo de dados capturados do Censo Escolar do INEP/MEC de 2018 que são aterradores:

Das 116,5 mil escolas de ensino infantil no Brasil (alunos de 0 a 6 anos), 8,5\% não possuem serviços essenciais de infraestrutura, como saneamento básico (acesso à água e coleta dos esgotos) e/ou energia elétrica. Significa dizer que quase 10 mil escolas não dispõem do que há de mais elementar. Somente $9,4 \%$ das creches e $12,6 \%$ das pré-escolas de zonas rurais possuem sistemas de esgotamento sanitário. Das 131,6 mil escolas do ensino fundamental (alunos de 6 a 14 anos), 41,6\% estão ligadas à rede de esgoto, 52,3\% dispõem apenas de fossa e em $6,1 \%$ não existe nenhum sistema de esgoto sanitário. Em $8,2 \%$ das unidades da rede fundamental —11 mil escolas— não há sequer um banheiro (CARLOS, 2020, s/p).

Tendo em perspectiva o distanciamento entre a realidade de estrutura das escolas e o que se propôs em termos de ensino remoto, durante a pandemia, queremos provocar a reflexão para as outras exclusões que interagem no contexto escolar. Refletir sobre as exclusões das diferenças que não estão listadas na Lei Federal no 13.146 (BRASIL, 2015). Ainda, alertar para as condições de "Inclusão" (aqui entre aspas muito destacadas) que se encontram as crianças e adolescentes referendados na lei acima citada. Ou seja, crianças e adolescentes com condições diferenciadas de aprendizagem ${ }^{2}$ que nunca tiveram contato com a tecnologia digital em suas escolas e, que não possuem dispositivos de conectividade em seus domicílios. Para essas crianças e adolescentes questiona-se: como estão interagindo e construindo conhecimento, seja em Matemática ou em qualquer outra disciplina?

\section{Considerações finais}

No cenário da Educação Matemática Inclusiva desenvolvemos uma pesquisa relacionada a educação de surdos, mais especificamente a produção de vídeo aulas de Matemática em Libras (GRÜTZMANN, ALVES e LEBEDEFF, 2020). Nossa escrita sobre inclusão puxou outra memória, esta em pertencente às duas autoras. Quando iniciamos o projeto a proposta era a produção de vídeo aulas de Matemática com tradução para a Libras. Entretanto, fomos duramente criticadas após a produção dos primeiros vídeos. Nossos vídeos eram acessíveis mas, não eram 
inclusivos. A educação inclusiva, como já apontava a Declaração de Salamanca, requer uma educação centrada na pessoa, os vídeos não estavam centrados no estudante surdo. Mudamos radicalmente o processo de produção. Nossos vídeos passaram a ser produzidos em Libras, para depois receberem a tradução para o Português através da adição de áudio e legenda. Desta forma, a "Inclusão", este conceito difuso, multifacetado, problemático, deu uma rasteira nas "Professoras Doutoras" cheias de boas ideias.

Nesse sentido, vale o questionamento: será que as nossas Licenciaturas estão, efetivamente, pensando em Inclusão? Será que discutem uma Educação Matemática para todos, que seja, de fato, inclusiva? Será que acadêmicos conseguem perceber que inclusão vai além do alunos surdo, cego ou cadeirante? Será que a minha instituição se preocupa com a formação dos professores que irão atuar na Educação Básica e que terão uma sala de aula ampla, cheia de diferenças, e ainda, muitas vezes, sem as condições estruturais e curriculares adequadas?

Skliar (1999) já avisava, na década de 90, que inclusão não poderia ser compreendida como sinônimo de matrícula e proximidade física, de localização do estudante:

... adverte-se nos discursos dominantes sobre a intenção de reduzir esse complexo e multifacético processo a uma experiência escolar, a contiguidade física das diferenças com aqueles chamados normais, no contexto de sala de aula (SKLIAR, 1999; p. 26).

Para o autor as diferenças se constroem histórica, social e politicamente. Nesse sentido, acreditamos que a Inclusão é, também, um mobilizador da história, da sociedade e, da política. Estando a diferença dentro da escola, temos que nos perguntar, a cada dia, se os professores e escolas realmente conhecem seus alunos. Perguntar quais as condições de produção do conhecimento que a escola está propondo para seus estudantes.

Vieira e Denari (2007) realizaram uma revisão bibliográfica de estudos sobre concepções e atitudes de crianças não deficientes em relação às deficiências e à inclusão. De acordo com as autoras os estudos indicam que as crianças parecem reproduzir as concepções vigentes na sociedade sobre as pessoas com deficiência, vendo-as como dependentes, incapazes, sem perspectivas de futuro e de uma vida plena. Além disso, a maioria dos estudos, em diferentes lugares do mundo, indicou que o contato com pessoas com deficiência e, o acesso a informações sobre a temá- 
tica podem contribuir para a construção de concepções e atitudes mais favoráveis. Nesse sentido, sugerem, o aumento da interação em ambientes inclusivos poderia gerar concepções e atitudes mais positivas e benefícios para todos os envolvidos. Quais as concepções e atitudes que estão sendo geradas na escola e, nos Cursos de Licenciaturas, com o modelo de Inclusão que temos disponível? Quais as memórias sobre Inclusão estamos construindo agora?

Durante a pandemia ocorreu o açodamento de uma prática desconhecida, para a qual nem docentes nem discentes estavam preparados. Houve a insistência no cumprimento de um tempo não transponível do presencial para a tela, de 800 horas letivas.Telas essas que muitas crianças e adolescentes deste Brasil não possuem e, muitas vezes, nem tiveram a oportunidade de conhecer. Não se sabe, ainda, quais os reais efeitos que esta prática terá nos estudantes, sejam eles os com diferenças ou os que representam a "norma”. Que possamos aproveitar o que estamos passando e aprendendo, com esta pandemia, para refletir, desconstruir e, reconstruir, o que entendemos por Inclusão. A escola, como a conhecemos, precisa ser discutida.

\section{Comments on school inclusion, math teaching and the pandemic}

\section{Abstract}

This paper aims to discuss the problems and reflect on the concept of inclusion in what concerns math teaching. To this end, it uses the authors' teaching memories as a backdrop to discuss teacher training, legal subsidies and the school's conditions for inclusion, both in pre-pandemic and pandemic context.

Keywords: School inclusion; inclusive math; inclusion during the pandemics.

\section{Notas}

1 PAEE - Público-Alvo da Educação Especial.

2 Porque apresentam um impedimento de longo prazo de natureza física, mental, intelectual ou sensorial, o qual, em interação com uma ou mais barreiras, pode obstruir sua participação plena e efetiva na sociedade em igualdade de condições com as demais pessoas (BRASIL, 2015). 
ABREU, B. M. Inclusão e Acessibilidade em tempos de Pandemia. Pedagogia em Ação, Belo Horizonte, v. 13, n. 1 (1 sem. 2020) - ISSN 2175-7003. 155

BRASIL/MAS. Coordenadoria Nacional Para Integração da Pessoa Portadora de Deficiência. Declaração de Salamanca e linha de ação sobre necessidades educativas especiais. Brasília: MAS/ CORDE, 1994.

BRASIL. Lei nº 13.146, de 6 de julho de 2015. Disponível em: http://www.planalto.gov.br/ccivil_03/_ato2015-2018/2015/lei/113146.htm Acesso em: 10 out. 2020.

BUENO, J. G. S. O Atendimento Educacional Especializado (AEE) como Programa Nuclear das Políticas de Educação Especial para a Inclusão Escolar. Tópicos Educacionais, Recife, v.22, n.1, jan./jun. 2016.

MEC. Parâmetros Curriculares Nacionais - Adaptações Curriculares. Brasília: Ministério da Educação, 1999.

CARLOS, E. Escolas sem banheiros e saneamento. Disponível em: http://www.tratabrasil.org.br/ edison-carlos-escolas-sem-banheiros-e-saneamento. Acesso em: 22 set. 2020.

MEC/SEESP. Portaria n. 1.793, de dezembro de 1994. Disponível em: http://portal.mec.gov.br/ seesp/arquivos/pdf/port1793.pdf. Acesso em: 22 set. 2020.

MEC/SEESP. Estratégias para a educação de alunos com necessidades educacionais especiais. Brasília: Ministério da Educação, Secretaria de Educação Especial, 2003.

CONSELHO NACIONAL DE EDUCAÇÃO. Câmara de Educação Básica. Resolução CNE/CEB 2/2001. Diário Oficial da União, Brasília, 14 de setembro de 2001. Seção 1E, p. 39-40.

FURG. Projeto Pedagógico do Curso de Licenciatura em Matemática. Disponível em: https://imef. furg.br/images/stories/documentos/PPC/PPCLic2019.pdf Acesso em: 23 set. 2020.

GRÜTZMANN, T. P. ALVES, R.S. e LEBEDEFF, T. B. A Pedagogia Visual na educação de surdos: uma experiência com o ensino da matemática no MATHLIBRAS. Práxis Educacional, 16(37), 51-74.

MENDES, E. G. Sobre alunos "incluídos" ou "da inclusão": reflexões sobre o conceito de inclusão escolar. In: Sonia Lopes Victor, Alexandro Braga Vieira e Ivone Martins de Oliveira (orgs.) Educação especial inclusiva: conceituações, medicalização e políticas. Campos dos Goytacazes, RJ: Brasil Multicultural, 2017.

NOGUEIRA, C. M. I. et al. Um panorama das pesquisas brasileiras em Educação Matemática Inclusiva: a constituição e atuação do GT13 da SBEM. Educação Matemática em Revista. Brasília, v. 24, n. 64, p.4-15, set./dez. 2019. Disponível em: http://sbem.iuri0094.hospedagemdesites.ws/revista/index.php/emr/issue/view/141. Acesso em: 13 out. 2020.

SKLIAR, C. A. Invenção e a Exclusão da Alteridade "deficiente" a partir dos Significados da Normalidade. Educação \& Realidade. v. 24, n. 2 (1999). p 15-32.

TEDESCO, J. C. Passado e presente em interfaces: introdução a uma análise sócio histórica da memória. Passo Fundo: Editora Universidade de Passo Fundo, 2011. 
TIC EDUCAÇÃO 2018. Pesquisa sobre o uso das tecnologias de informação e comunicação na escolas brasileiras. São Paulo: Comitê Gestor da Internet no Brasil, 2019. Disponível em: https:// cetic.br/media/docs/publicacoes/216410120191105/tic_edu_2018_livro_eletronico.pdf Acesso em: 15 out. 2020 .

UNIPAMPA. Projeto Pedagógico do Curso de Matemática - Licenciatura. Disponível em: http:// dspace.unipampa.edu.br/bitstream/riu/89/6/PPC\%20Matem\%C3\%A1tica_Bag\%C3\%A9.pdf Acesso em: 23 set. 2020.

VIEIRA, C. M. e DENARI, F. E. O que pensam e sentem crianças não deficientes em relação às deficiências e à Inclusão: revisão bibliográfica. Educação e Contemporaneidade, Salvador, v. 16, n. 27, p. 31-40, jan./jun., 2007.

VEIGA-NETO, Alfredo; LOPES, Maura Corcini. Inclusão e governamentalidade. Educ. Soc. , Campinas, v. 28, n. 100, pág. 947-963, outubro de 2007. Disponível em <http://www.scielo.br/ scielo.php?script=sci_arttext\&pid=S0101-73302007000300015\&lng=en\&nrm=iso $>$. acesso em 07 de outubro de 2020. 